\title{
Editorial
}

\section{COMMON FEATURES IN RAPIDLY DECLINING LEPROSY EPIDEMICS}

Many leprosy workers devote years of their lives to their chosen profession without seeing any marked change in the amount of leprosy around them. To the fortunate $\mathrm{few}$ is given the privilege of witnessing a progressive decline in the prevalence of active leprosy, which, beginning almost tentatively, gains in momentum year by year, and in a comparatively short time becomes unmistakable and even massive. In this Number of the Review, Dr J.N. Rodriguez, doyen of Philippine leprologists, describes such an experience in the island of Cebu.

The Philippines Republic was particularly blessed in the earlier years of this century in having a government prepared to spend considerable sums on leprosy control, and a succession of distinguished leprologists notable for their careful field work. The findings they report are in the highest degree trustworthy, and are briefly as follows. During the period ${ }^{n} 05$ to 1955 a very substantial decline occurred in the prevalence of leprosy in cebu. Between 1920 and 1940, in an area under intensive observation, the incidence of lepromatous leprosy declined by $60 \%$. Although at first the incidence of non-lepromatous leprosy increased, later it also declined, and between the years 1930 and 1955 the total recorded number of people with active leprosy fell from 5290 to 2882 , a fall of $46 \%$ in 25 years. Sulphone treatment became routine in 1955 .

This is of course not an isolated phenomenon. Other examples from the pre-sulphone era include Norway (Lie, 1929), Nauru (Bray 1930; Wade and Ledowsky, 1952) and E. Nigeria (Davey et al., 1956; Davey, 1957). Thailand, Khon Kaen Province, is a more recent example. The first stage in the process, namely the decline in incidence of lepromatous leprosy, is now a feature of several modern leprosy control programmes. A comparison between the situations prevailing in the various areas where this phenomenon has occurred immediately reveals that while there is no single pattern common to them all, there are important common features.

The most important question posed by such events is how far they can be attributed to the natural course of leprosy in the situations concerned, and how far human intervention played some part. Epidemics rise and fall, sometimes rapidly, sometimes slowly, as the result of the complex interplay of many factors in a dynamic constantly changing situation. The disappearance or attenuation of the infecting agent, the development of resistance to it, whether attained through genetic influences or acquired by repeated contact with it, all these are part of the picture.

Some attenuation of the bacillus has been suggested as a possible explanation for the burning out of leprosy infection af ter many years even in patients with lepromatous type leprosy. Even if true, this could not account for rapid change in the course of the disease in the community. Of greater relevance is the possibility of differences in pathogenicity between one strain of Myco. leprae and another, with short lived epidemics caused by a mild strain. In this issue, Job et al. of fer 
evidence of a difference in pathogenicity in the mouse between one strain of the bacillus and others in India. Hitherto, strains of $M y c o$. leprae from different parts of the world have produced similar pathogenic effects in mice. While not ignoring the possibility, it does not seem likely that attenuated strains of the bacillus can account for rapidly declining epidemics in places as far apart as Northern Europe, West Africa, S.E. Asia and Oceania.

Natural resistance involves genetic factors. Molesworth (1933) in a detailed study of natural selection in leprosy considers this an important influence, but only operative through succeeding generations. It could not account for major changes within the span of 25 years.

When considering the development of acquired resistance, and in particular the influence of tuberculosis, we are on much more solid ground. The prevalence of leprosy in all the areas quoted was well above the threshold at which exposure to My'co. leprae by the whole population is possible. While initial exposure could account for the high susceptibility of all age groups, the relative frequency of indeterminate and maculo-anaesthetic types of leprosy, and the infrequency of polar forms, repeated exposure would tend to encourage self-healing and a shift towards the tuberculoid end of the spectrum. The clinical leprosy seen in Nauru, Cebu and E. Nigeria would all suggest an early phase in the epidemic rather than a late stage, with increasing polarisation and fewer clinical cases as the epidemic declined, the whole process of rise and fall condensed into a relatively short period.

During the period under review, the Philippines was experiencing a massive epidemic of tuberculosis. Canzares (1948) gives the death rate from tuberculosis before the 1941-45 war as 230 per 100,000 population, and estimated that in 1948 no fewer than 500,000 out of a population of 18 millions had active tuberculosis. It must be presumed that a very high proportion of the population of Cebu was exposed to Myco. tuberculosis, that those unable to develop resistance to it died of it, and among the remainder it is at least probable that tuberculin sensitivity gave enhanced protection against Myco. leprae, thus providing an important element in the decline of the disease. Where Norway is concerned it is inconceivable that a disease so prevalent in N.W. Europe had passed Norway by, especially with Bergen being one of the cities of the Hanseatic League. The influence of tuberculosis could also have been considerable there. I have not been able to find data relating to tuberculosis in Nauru, but the pattern of leprosy there does not favour heavy involvement with tuberculosis (Leiker, 1960). In Nigeria however, a tuberculin and lepromin survey of an area where leprosy had been under close observation for 15 years gave in 1955 an adult plateau level for 10TU tuberculin of $65 \%$, a figure not consistent with any long experience of tuberculosis, and indeed clinical tuberculosis was still a rare disease at that time (Davey et al., 1958). Where the interplay of tuberculosis and leprosy is concerned, we need to remember that whereas both diseases spread along trade routes, it is possible to have very heavy involvement of tuberculosis along such routes with negligible involvement in static rural communities quite nearby. If tuberculosis is a factor in the decline of leprosy in such communities, its introduction there and a consequent high incidence must first have taken place. Tuberculosis is an important but inconstant factor in this story.

Reference is appropriate at this point to malnutrition and debility. Lie relates apparent periodic increases in the prevalence of leprosy in Norway to periods of economic hardship. Rodriguez on the other hand quotes the example of a locality 
under close observation where serious economic hardship had no observable effect on the prevalence of leprosy. When it is recalled that the period with which we are concerned included both the economic stringency of the 1930's and the disastrous war years, it would appear that in the Philippines as in many other places there was no direct link between leprosy and economic deprivation.

Turning to human intervention in the leprosy epidemic, in the year 1907 legislation came into force in the Philippines providing for the compulsory isolation of people with multibacillate types of leprosy in the island of Culion. At one time 7000 patients were isolated there. Throughout the period under consideration we have to envisage the steady removal from the island of Cebu of people who were a source of leprosy infection to others, and this is one obvious explanation for the decline in leprosy observed. In Nauru, although $90 \%$ of patients were classified as suffering from leprosy of maculo-anaesthetic type, no less than 189 out of 368 patients were classified as infective and isolated. Isolation was thus intensive, and included all patients liable to degenerate towards the lepromatous end of the spectrum. Compulsory isolation is by general consent an inefficient method of leprosy control, not only because compulsion encourages concealment, but because early lepromatous cases are liable to be discharging large numbers of viable $M y c o$. leprae from their noses into the environment long before the disease is sufficiently obvious to bring them within the legal net. A unique element nevertheless arises in the areas of leprosy decline which concern us. In the Philippines, patients obviously liked living at Culion. The small size of Nauru made the oversight of isolation there a simple problem. In Nigeria, a much more liberal system made the isolation of the same types of patient a matter of public opinion and personal choice, but there these methods worked, and almost all open cases voluntarily isolated themselves. In Norway, although only $10 \%$ of patients were isolated in hospitals, the principles of home isolation were effectively applied, according to Lie (1929). We have here the first thread binding all these examples together.

Was treatment a factor? In Norway it certainly was not, but in Cebu, Nauru and E. Nigeria a high proportion of all patients received treatment with chaulmoogra or hydnocarpus oil or their derivatives. In my experience in Nigeria, hydnocarpus oil had little effect in established lepromatous leprosy, but it was the general consensus of opinion among leprologists in those days that hydnocarpus oil did have some effect in encouraging resolution, and so preventing some indeterminate and early borderline cases from degenerating into the lepromatous type. This was certainly the opinion of Rodriguez and of leprologists in Nauru.

In my judgement, the chief virtue of hydnocarpus oil lay in a different direction. At a time when Western medicine was being appreciated for the first time, in particular forms of treatment by injection, hydnocarpus oil popularized leprosy treatment, and encouraged patients to come forward in large numbers in the early stages of their disease.

This leads us immediately to what I believe is the second thread linking these events, and one rarely given the significance it merits. In every example quoted we have a situation where ignorance and prejudice were replaced by reason, and in the atmosphere of cooperation so generated, patients felt able to come forward without fear and cooperate on a large scale in the measures provided. Lie regards this factor as of great importance in Norway, though there it was the understanding of the infectivity of leprosy which replaced the concept that leprosy was non-infectious. In Nauru the entire population was examined at 
monthly intervals. Excellent cooperation was given in Nigeria and in areas under close observation in the Philippines.

Nowhere did an informed leprosy consciousness come by accident. It had to be won by sustained intensive effort, as Rodriguez indicates.

The lesson for us is obvious. While acknowledging fully the importance of immunological factors which operate quite apart from leprosy control measures, there are two common threads linking together the examples quoted of a rapid decline in leprosy in pre-sulphone days, both derived from human intervention. The first is the isolation of infective and potentially infective cases, the second a successful campaign of public education. Both have their modern counterparts. Sulphone therapy, by its speedy action on infection of the nose and throat has largely replaced isolation as an effective means of removing from public circulation large numbers of viable Myco. leprae. The other determining factor, the large scale cooperation of public and patients alike is as relevant as ever it was, and as in the past, it still has to be won. The maximal extension of sulphone treatment, and a skilled sustained campaign of leprosy education are priorities for us all.

\section{References}

Bray, G. (1930), Proc. R. Soc. Med. Section Trop. Dis. 23, 1370.

Canzares, M. (1948). Amer. Rev. Tubercul. 57, 149.

Davey, T. F., Ross, C. M. and Nicholson, B. (1956). Brit. Med. J. 2, 65.

Davey, T. F. (1957). Int. J. Lepr. 25, 329.

Davey, T. F., Drewett, S. E, and Cynthia Stone (1958). Lepr. Rev. 29, 81.

Leiker, D. L. (1960). Lepr. Rev. 31, 241.

Molesworth, E. H. (1933). Int. J. Lepr. 1, 265.

Lie, H. P. (1929). Trans. R. Soc. Trop. Med. Hyg. 22, 357.

Wade, H. W. and Ledowsky, V. (1952). Int. J. Lepr. 20, 1.

T. F. Davey 